\title{
Prospective Audit to Study Syner-KINASE use to restore Patency in Occluded CentRal Venous CaTheters (PASSPORT study) in haematology and oncology patients- Interim Results
}

Mick Kumwenda, Dr ${ }^{1}$, Steve Hill, RN², Lisa Dougherty, RN ${ }^{3}$, Andrew Jackson, RN ${ }^{4}$

${ }^{1}$ Glan Clwyd Hospital Rhyl, Renal, St Asaph, UK, ${ }^{2}$ The Christie NHS Foundation Trust, Procedure Team, Manchester, UK, ${ }^{3}$ Formerly The Royal Marsden NHS Foundation Trust, IV Team, London, UK, ${ }^{2}$ The Rotherham NHS Foundation Trust, Vascular Access Team, Rotherham, UK and Director IVTEAM.com

\section{INTRODUCTION AND AIM}

Haematology and oncology patients often require regular intravenous treatments. For this group of patients a reliable central venous access device (CVAD) is a necessity that facilitates this treatment. The types of CVAD utilised in these patients include peripherally inserted central catheters (PICC), tunnelled central catheters and implantable ports. CVAD dysfunction can lead to delays or failures in treatment and additional clinical interventions such as CVAD removal. CVAD patency is an essential component of care in this group of patients. CVAD dysfunction often associated with thrombosis is defined as a) the inability to administer treatments due to total occlusive (TO) or b) Persistent Withdrawal Occlusion (PWO). Early intervention with thrombolytic agents is imperative to maintain CVAD patency in order to avoid disruption of life saving treatments. A multidisciplinary focus group was formed in the UK to address this issue and offer guidance in the management of suspected catheter thrombosis using standardised Syner-KINASE dose regimens.

\section{METHODS}

Heamatology and oncology centers that use Syner-KINASE as a thrombolytic agent took part in a prospective audit of management of dysfunctional CVADs to determine safety and efficacy of Syner-KINASE. Once approval was granted by audit committees prospective data was collected anonymously using a secure web based research data capture system (REDCap) from September 2017 until March 2018. Type of occlusive episode requiring treatment was described (TO or PWO).

\section{RESULTS}

Participatin

\section{g centres}

Total $n=138$

number of - Females $n=65(47.1 \%)$

patients Males $n=73(52.9 \%)$

\section{Age}

Type of
CVAD

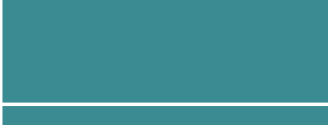

CVAD site

of

placement

\section{Baseline data}

\section{8}

02-92 years (mean 54.3$)$

- $\operatorname{PICC} n=115(83.3 \%)$ tunnelled) $n=1(0.7 \%)$

- Basilic $n=84(60.9 \%)$

- Brachial $n=25(18.1 \%)$

- Jugular $n=11(8.0 \%)$

- Subclavian $n=11(8.0 \%)$
- Implanted ports $\mathrm{n}=15$ (10.9\%)

- Skin-tunnelled catheter $n=6(4.3 \%)$

- Midline catheter $n=1(0.7 \%)$

- Short-term central venous catheter (non-

- Antecubital fossa $n=4(2.9 \%)$

- Unknown $n=2(1.4 \%)$

- Cephalic $n=1(0.7 \%)$

\section{Intervention data}

\begin{tabular}{|c|c|}
\hline $\begin{array}{l}\text { Number of } \\
\text { interventions }\end{array}$ & $\begin{array}{l}\text { - One intervention } n=114(83 \%) \\
\text { - } \quad \text { Two interventions } n=18(13 \%) \\
\text { - } \quad \text { Three interventions } n=4(3 \%) \\
\text { - Eight interventions } n=2(1 \%)\end{array}$ \\
\hline $\begin{array}{l}\text { Occlusion } \\
\text { type }\end{array}$ & $\begin{array}{l}\text { - Persistent Withdrawal Occlusion (PWO) } n=76(55 \%) \\
\text { - Total Occlusion (TO) } n=62(45 \%)\end{array}$ \\
\hline $\begin{array}{l}\text { PWO dose } \\
\text { (\% success) }\end{array}$ & $\begin{array}{l}5,000 \text { IU } n=37(30=81 \%), 10,000 \text { IU } n=27(21=78 \%), \\
25,000 \text { IU } n=6(5=83 \%), \text { Other } n=4(3=75 \%) \\
\text { Unreported } n=1(1=100 \%)\end{array}$ \\
\hline $\begin{array}{l}\text { Overall PWO } \\
\text { success }\end{array}$ & - $80 \%$ success rate for first intervention \\
\hline $\begin{array}{l}\text { TO dose }(\% \\
\text { success })\end{array}$ & $\begin{array}{l}5,000 \text { IU } n=46(41=89 \%), 10,000 \text { IU } n=5(5=100 \%), \\
25,000 \text { IU } n=3(3=100 \%), \text { Power flush } n=2(2=100 \%) \text {, } \\
\text { Unreported } n=6(4=67 \%)\end{array}$ \\
\hline $\begin{array}{l}\text { Overall TO } \\
\text { success }\end{array}$ & - $89 \%$ success rate for first intervention \\
\hline
\end{tabular}

\section{OVERALL OUTCOME}

Catheter occlusion clearance rates for PWO and TO combined were $84.5 \%$ and $84 \%$ after first and subsequent interventions respectively.

\section{SAFETY \& TOLERABILITY}

No adverse effects were reported in this audit.

\section{DISCUSSION}

Despite urokinase being used for CVAD occlusion for many years, there are no agreed guideline(s) or optimal dose protocols that have been developed or endorsed by national or international professional organisations. This prospective audit shows promising results to assist clinicians in reaching consensus on thrombolytic protocols for the use of Syner-KINASE for occluded CVADs.

\section{CONCLUSION}

In this prospective audit treatment of occluded CVAD with Syner-KINASE was safe and effective in restoring patency of CVAD. Further analysis will follow after completion of the study.

\section{ACKNOWLEDGEMENTS}

The authors would like to thank the Steering Committee, Participating centres, Dr. Aurangzaib Khawaja for data collection, Peter Nightingale for statistical analysis, and Syner-Med PP. Ltd for secretariat support.

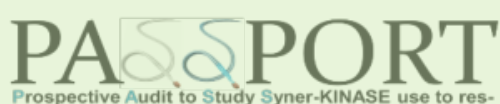

